Schultz, C. J., G. T. Stano, P. J. Meyer, B. C. Carcione, T. Barron, 2017: Lightning decision support using VHF total lightning mapping and NLDN cloud-to-ground data in North Alabama. J. Operational Meteor., 5 (11), 134-145,

doi: https://doi.org/10.15191/nwajom.2017.0511

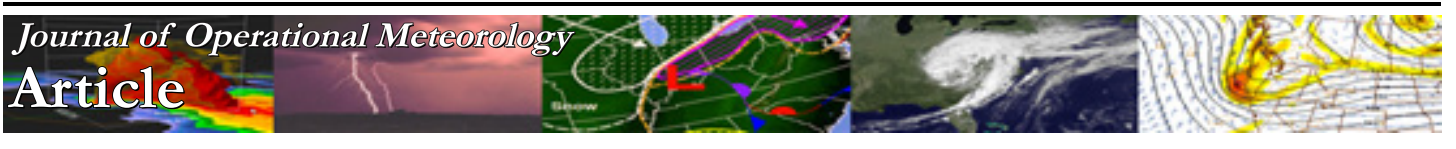

\title{
Lightning Decision Support Using VHF Total Lightning Mapping and NLDN Cloud-to-Ground Data in North Alabama
}

\author{
CHRISTOPHER J. SCHULTZ \\ Earth Science Branch, NASA Marshall Space Flight Center, Huntsville, AL \\ GEOFFREY T. STANO \\ NASA SPoRT/ENSCO Inc., Huntsville, AL \\ PAUL J. MEYER \\ Earth Science Branch, NASA Marshall Space Flight Center, Huntsville, AL \\ BRIAN C. CARCIONE, TODD BARRON \\ National Weather Service, Huntsville, Huntsville, AL
}

(Manuscript received 19 December 2016; review completed 8 May 2017)

\begin{abstract}
This study focuses on lightning safety applications at NASA's Marshall Space Flight Center in preparation for the use of new Geostationary Lightning Mapper data once operational in 2017 from GOES-16. A total of 13 years of North Alabama Lightning Mapping Array and National Lightning Detection data are analyzed for lightning safety applications. Data are analyzed using three range ring criteria used by the Marshall Space Flight Center Emergency Operations Center for monitoring and warning on lightning hazards (32-km, 16-km and 9-km). Approximately $75 \%$ of the time, the total lightning observations from the North Alabama Lightning Mapping Array provide additional lead time on the first cloud-to-ground flash, with the 25th to 75 th percentile of these lead times between 0 and 23 minutes. The use of NALMA also incurs additional downtime of up to 36 minutes versus the use of cloud-to-ground data alone. Seventy-nine percent of the time that lightning is detected by the lightning mapping array in the 16-km range ring, lightning also is observed to impact Marshall Space Flight Center directly. Thirty percent (309/1043) of these events inside the 16-km range ring do not contain a cloud-to-ground flash, but continue to pose a threat to personnel and property. Thus, the threat of lightning is likely under-realized to the public because safety criteria are often based on cloud-to-ground data alone. Minor seasonal differences in lead time are observed, with the most notable difference between autumn and winter, where a Wilcoxon-Mann-Whitney independence test yield a p-value of 0.0076.
\end{abstract}

\section{Introduction}

Most lightning safety initiatives over the last several decades have utilized the National Lightning Detection Network (NLDN; Orville, 2008, Cummins and Murphy 2009, Nag et al. 2015) for lightning safety applications. These are point data sources, which provide the end user an idea of the exact location of a ground flash, the polarity of that ground flash, and its magnitude. Decision support tools have been developed from this type of data for airport weather warnings, outdoor operations, large event venue support, and incident support (e.g., Holle et al. 1999, Gratz and Noble 2006, Stano et al. 2010, Holle et al. 2016). Recent inclusion of the in-cloud (IC) detections by both the NLDN and the Earth Networks Total Lightning Network (ENTLN; Liu and Heckman 2012, Thompson et al. 2014, Rudlosky 2015, Bitzer et al. 2016) have increased the amount of lightning data detected by these systems. The inclusion of the IC flash information has shown an increase in 
the probability of prediction of the first CG flash for lightning safety (e.g., Holle et al. 2016).

Work by Holle et al. (2016) demonstrated how the use of IC lightning data from the NLDN would affect performance metrics at 10 airports across the country. Holle et al. (2016) showed additional IC data increased the probability of detection (POD) of the first CG by $13 \%$, while keeping the false alarm ratio (FAR) very similar to CG-only numbers. Furthermore, they experimented by altering warning range rings for various airports around the country from $4.8-\mathrm{km}$ to 0.5 $\mathrm{km}$. Holle et al. (2016) found that reducing the warning area for this ring increased the POD, but increased the FAR substantially.

The one characteristic of lightning underutilized in safety studies is the three-dimensional information some lightning measurements can provide to increase situational awareness. Spatial extent of lightning flashes is important for lightning safety decision support because some flashes can travel tens to hundreds of km (Kuhlman et al. 2009, Weiss et al. 2012, Lang et al. 2016) or can come to ground outside of precipitation structures observed on radar (i.e., bolts from the blue, Tran et al. 2014). Figure 1 illustrates an example of how total lightning observations from the North Alabama Lightning Mapping Array (NALMA; Rison et al. 1999; Koshak et al. 2004) has aided decision support for the National Weather Service (NWS) Huntsville. Blue and magenta diamonds represent the location of NLDN derived flash detections (CG flash, blue diamond, IC flashes magenta diamonds), while the dots are very high frequency (VHF) information from the NALMA that shows the path of the lightning flash in time. Note that closest NLDN locations are $\sim 50 \mathrm{~km}$ from two airports (Huntsville International Airport [KHSV], Redstone Army Airfield [RSA]) and the Panoply Arts Festival (30-50 thousand people at any given point in time), while the NALMA information is showing lightning activity above these three locations.

Differences in the time of the first IC flash and the first $\mathrm{CG}$ flash have been analyzed for individual storms. Buechler et al. (2009) and MacGorman et al. (2011) combined NLDN and VHF source points from lightning mapping arrays (LMAs) in Northern Alabama and Central Oklahoma to determine the distribution in time between lightning initiation and the production of the first CG in thunderstorms. Buechler et al. (2009) found that the average lead time on first CG flash from the LMA was 4 min and that nearly $18 \%$ of the 109 storms examined produced a CG flash as their

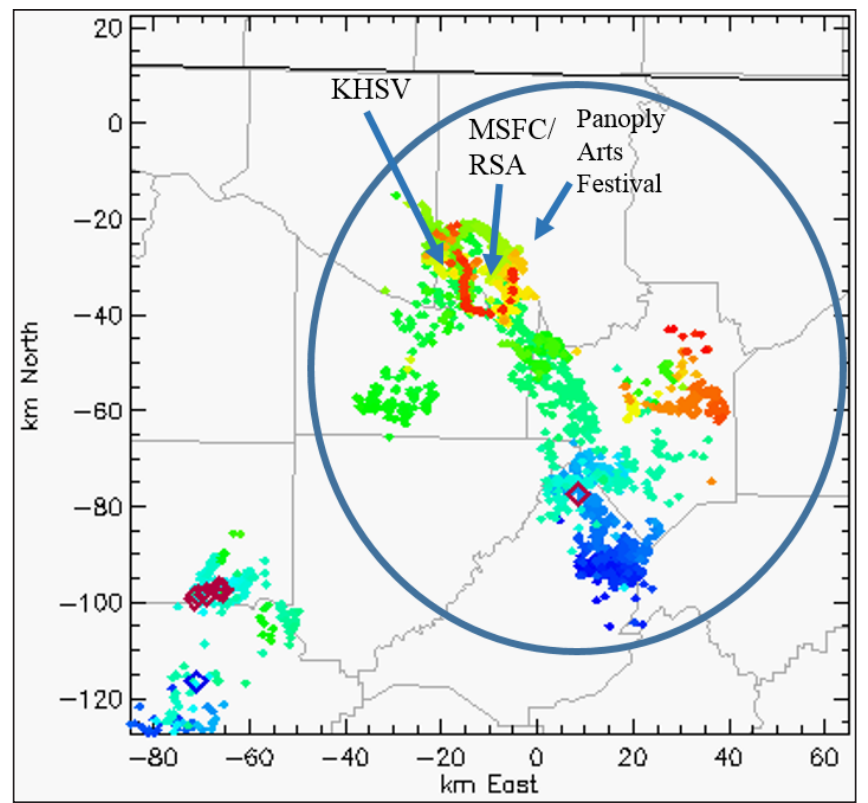

Figure 1. An LMA flash at 00:01:50 UTC 28 April 2013 near Huntsville, Alabama, using the NALMA. The blue circle indicates the flash of interest at this point in time. VHF sources from the LMA are represented by the colored dots and the plot is centered relative to the NALMA center. Blue dots represent VHF sources that occur earlier in the lightning flash, while red dots are VHF source detections later in the lightning flash's lifetime. The blue diamond represents the location of CG detections by the NLDN and magenta diamonds represent IC detection of lightning detected by the NLDN during this three second period. Arrows point toward key decision support locations on this day: Huntsville International Airport (KHSV), MSFC/RSA and the Panoply Arts Festival. Click image for an external version; this applies to all figures hereafter.

first lightning flash. MacGorman et al. (2011) found similar lead times on the order of 5-10 min for more than $50 \%$ of their storm sample. They determined that $10-20 \%$ of their storm sample did not produce a CG even though there was lightning activity detected by the LMA. MacGorman et al. (2011) also found regional differences in lead time in their examination of storms on the High Plains versus those in North Texas and Oklahoma. Importantly, these findings are not applied to a fixed location to determine the impact of the IC flash detections on lightning safety protocols.

Therefore, the present study specifically examines how three-dimensional information on lightning from systems such as an LMA are applicable to lightning safety initiatives of an emergency operations center. 
The goal of the study is to understand the following questions relative to site specific location.

1) How much additional lead time does the threedimensional NALMA data provide on the first CG flash at Marshall Space Flight Center (MSFC)?

2) How often does the LMA observe lightning over MSFC, but a CG flash is not observed to occur within the lightning warning domain?

3) What is the amount of additional down time incurred using the LMA for lightning safety operations versus the previous CG networkonly configuration?

4) What are similarities and differences in lead time between prediction of first $\mathrm{CG}$ flash in a thunderstorm (i.e., Eularian framework) versus applying these data to location specific decision support (i.e., Lagrangian framework)?

Discussion also will be presented about the opportunities and challenges of extending these findings to GOES-16's Geostationary Lightning Mapper (GLM; Goodman et al. 2013). This work directly supports the Emergency Operations Center (EOC) at MSFC, which has the primary responsibility to notify operational entities and employees of the threat of lightning to MSFC.

\section{Data and Methods}

There are two types of lightning data utilized in this study. The first is the NLDN network that has been used by the NWS for more than 25 years for lightning decision support. The second is the NALMA, which is currently used to devise proxy datasets for the arrival of the new GLM instrument. For a complete discussion of various lightning detection methods and intercomparision of detection systems, please review Cummins and Murphy (2009), Nag et al. (2015) and Bitzer and Burchfield (2016).

1) Data

a. The National Lightning Detection Network

The NLDN has been used operationally for lightning safety applications for several decades (e.g., Cummins and Murphy 2009). The NLDN operates in the low frequency range between 1 and $350 \mathrm{kHz}$ and consists of 113 sensors across the United States (Buck et al. 2014). The NLDN has a reported detection efficiency of CG flashes between 90 and $95 \%$, with spatial errors in CG location that are typically $<500$ m (Cummins and Murphy 2009, Buck et al. 2014, Koshak and Solakiewicz 2015, Nag et al. 2015). Only CG information from the NLDN is used in this study because the IC flash detections the NLDN now incorporate into their data are not present for the entire period of analysis. It is estimated that the NLDN can detect $40-50 \%$ of IC lightning (Buck et al. 2014, Nag et al. 2015). For an example of the application of IC lightning information from the NLDN, please see Holle et al. (2016).

\section{b. The North Alabama Lightning Mapping Array}

The NALMA is a VHF lightning detection network that operates in the $76-82 \mathrm{MHz}$ frequency range. The NALMA currently consists of 11 stations across North Alabama, and uses time of arrival techniques to detect the electrical breakdown associated with lightning (e.g., Rison et al. 1999, Koshak et al. 2004, Cummins and Murphy 2009). This system has been operational since March of 2002 and provides nearly 14 years of continuous data for use to assess how GLM measurements might impact lightning decision support services. The NALMA locates the mean position of a lightning flash in $80 \mu$ s intervals (e.g., colored dots in Fig. 1) and these locations are termed VHF source points. VHF source points are then combined using spatial criteria of 0.5 radians and a time criteria of $0.3 \mathrm{~s}$ to identify VHF source points associated with a single flash (McCaul et al. 2009). All VHF source points that meet these criteria are grouped into a single flash and a minimum of 10 VHF source points must be associated with a lightning flash for this analysis. The UTC time of the first VHF source point in each flash is then utilized as the NALMA flash time for this analysis.

\section{2) Methods}

The integration of both lightning datasets for this project requires a multi-step process to combine the NLDN data with the NALMA dataset to provide accurate lead time estimates and number of NLDN events per NALMA flash. Therefore, the following steps were taken to assess the impact of NALMA observations for decisions support:

a. 13 years of NALMA VHF source data were taken and processed through the McCaul et al. (2009) flash algorithm. All flashes with VHF source numbers $\geq 10$ sources per flash were kept for analysis and gridded to a $100-\mathrm{km}$ 
by $100-\mathrm{km}$ by $1-\mathrm{km}$ domain centered at the NALMA center $(34.72461,-86.64533)$.

b. 9, 16 and 32-km range rings were constructed and centered on MSFC (34.661304, -86.671277). The 16 and 32-km distances represent the alert and action stages for MSFC's EOC to respond and notify employees and operational activities. The 9-km ring was used to validate that lightning occurred on Redstone Arsenal (RSA) property, which encompasses MSFC.

c. The NALMA flash time was subtracted from the NLDN CG flash time to compute lead time in the 9,16 and $32-\mathrm{km}$ ranges rings. If the first NALMA flash and NLDN flash occurred simultaneously, a lead time of zero min was recorded. Median, 25th and 75th percentiles for lead times were computed from these differences in time. The analysis was broken down by seasons to determine if any notable differences in timing were observed based on time of year.

\section{Analysis}

The analysis period for this data was between 1 January 2003 and 30 September 2015, a total of 4,656 days. Of the 4,656 days, a total of 2,169 days (46\%) had total lightning activity observed from the NALMA within $100 \mathrm{~km}$ of MSFC. The NALMA observed activity over MSFC on only $38 \%(823 / 2,169)$ of the days where lightning activity was observed within 100 $\mathrm{km}$ of MSFC during this 13-yr period.

\section{a. Lead Time and Additional Time Under Lightning Warning}

Lead time analysis focused on the additional time the NALMA data provides prior to the first identification of a CG flash by the NLDN, for the three range rings used for lightning warnings at MSFC. Figure 2 depicts the additional number of minutes that were gained by using total lightning observations in the $9-\mathrm{km}, 16-\mathrm{km}$ and 32-km range criteria. Figure 2 shows that additional lead time provided by NALMA was consistent across all three range criteria. The 25 th percentile lead times observed for the three ranges were on the order of 30 to $90 \mathrm{~s}(25 \mathrm{~s}, 63 \mathrm{~s}, 88 \mathrm{~s})$, the medians were between 7 and 9 min, and the 75th percentile lead time was between 21 and 23 min (Fig. 2, Table 1). Wilcoxon-Mann-Whitney

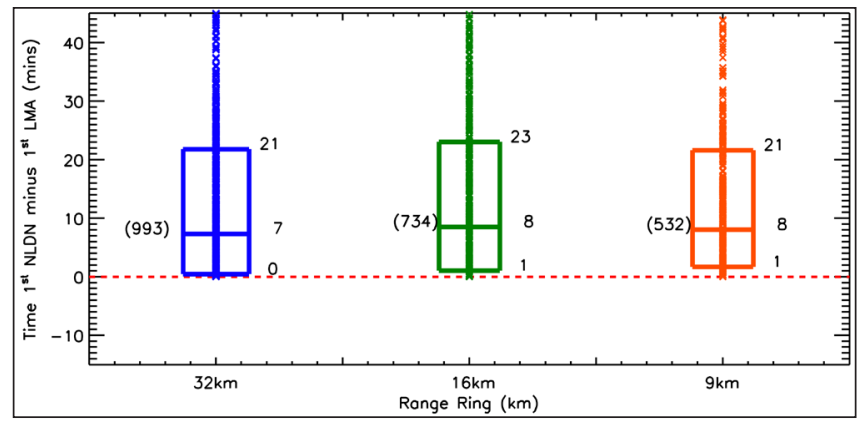

Figure 2. Box plots of time elapsed between first NALMA detected flash in the 32, 16, and 9-km range rings and the first $C G$ flash detected within these distances from MSFC. Numbers contained in parentheses to the left of each box indicate the number of days examined at these ranges, while the numbers to the right represent the 25th, median, and 75th value for lead time (CG time minus NALMA time) in minutes. ' $\mathrm{X}$ ' marks represent individual data points within the sample.

(WMW; Wilks 1995) Rank Sum hypothesis testing indicates that the lead time populations significantly overlap (Table 2).

Additional time under a lightning warning using NALMA data was examined (Fig. 3). Additional time that lightning was observed within the three different rings ranged from 1 to $4 \mathrm{~min}$ at the 25th percentile to upwards of 30-36 min at the 75th percentile (Fig. 3, Table 1). WMW Rank Sum hypothesis testing once again indicated that the lead time populations significantly overlap (Table 1).

Seasonal differences in lead time were examined because of differences in dominant convective morphology throughout the year in North Alabama (Smith et al. 2012). Small differences in lead time in the median and 75th percentile were noted between the winter (December-February), spring (MarchMay), summer (June-August) and autumn (SeptemberNovember). Figure 4 and Table 3 show the 25th, median and 75 th percentile lead times for each season. The most notable difference in season was the transition from autumn to winter using WMW rank sum ( $Z$ score of 2.42, one tailed p-value of 0.0076 ). The 25 th, median and 75 th percentile lead times for autumn are 3,13 and $26 \mathrm{~min}$, while those for winter are 0,5 and $20 \mathrm{~min}$. The transition from summer to autumn was the second most statistically different lead time distributions ( $\mathrm{Z}$ score 2.25 , p-value 0.0122 ), with $6 \mathrm{~min}$ difference in the median lead time between summer and autumn. Spring 
Table 1. Number of days with lightning activity, 25th percentile, median and 75th percentile lead times and additional time under warning in minutes for the 3 range criteria of 32-km, 16-km and 9-km for MSFC lightning safety protocol.

\begin{tabular}{|l|r|r|r|}
\hline \multicolumn{1}{|c|}{ Range (km) } & 32-km & 16-km & \multicolumn{1}{c|}{$9-\mathrm{km}$} \\
\hline Number of Days & 1298 & 1043 & 823 \\
Lead Time (25th) & 0 & 1 & 1 \\
Lead Time (median) & 7 & 8 & 8 \\
Lead Time (75th) & 21 & 23 & 21 \\
Additional Time (25th) & 0 & 2 & 4 \\
Additional Time (median) & 9 & 13 & 17 \\
Additional Time (75th) & 30 & 30 & 36 \\
\hline
\end{tabular}

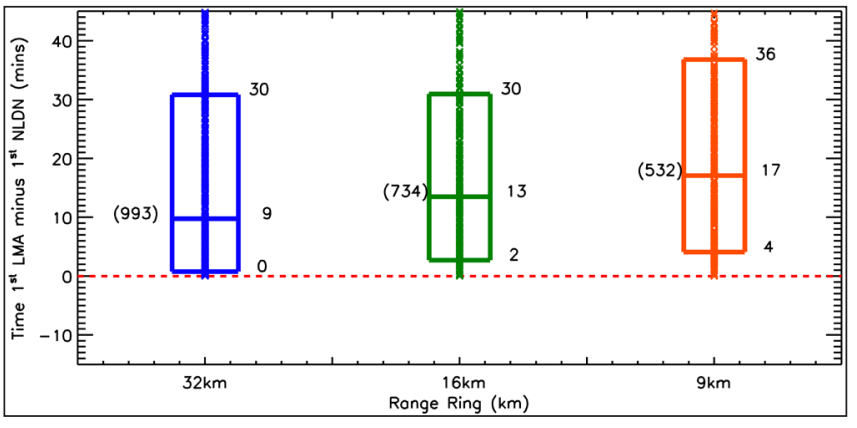

Figure 3. Same as Fig. 2, but for additional time MSFC would remain under the lightning warning criteria if the NALMA data are used instead of the CG only dataset.

and summer seasons had lead time distributions that were the most similar. The $\mathrm{Z}$ score for this comparison was 0.35 , with a p-value of 0.3616 and the 25 th, median and 75th percentile lead time values were within 1 to 3 min of each other. Comparing the transition seasons of spring and autumn also showed differences that neared the $\mathrm{p}=0.10$ (two tailed) independence level ( $\mathrm{Z}$ score 1.6033, p-value 0.0544).

\section{b. Detection of CG flashes using NALMA data}

Statistics were computed for each of the 3 ranges to analyze the number of times both NALMA and NLDN were observed in the same range rings (Table 3). Of the 1298 days when lightning was observed in the 32$\mathrm{km}$ range ring, 993 of them contained a NALMA and NLDN detection ( $77 \%$ correct prediction of a CG; $\mathrm{CP})$,

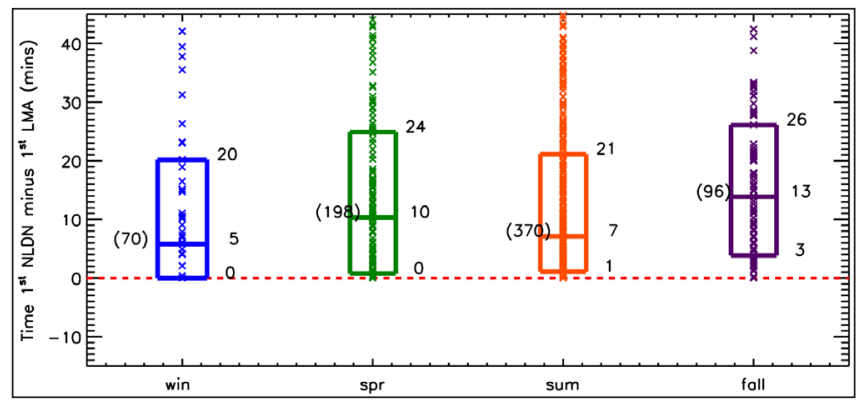

Figure 4. Same as Fig 2, but with lead time values broken down by season.

while 305 only contained a NALMA detection $(23 \%$ false prediction of a CG; FP). At 16-km these numbers were $734 / 1043(70 \% \mathrm{CP})$ and 309/1043 (30\% FP), respectively. At $9-\mathrm{km}$, the percentage of the time where both NALMA and a CG from the NLDN were detected decreased to $65 \% \mathrm{CP}(532 / 823)$ and $35 \% \mathrm{FP}(291 / 823)$.

Analysis was extended to determine the number of times that lightning occurred in the $16-\mathrm{km}$ range ring (action) and the 9-km range ring (impact to MSFC/ RSA). Of the 1043 days where lightning was observed to occur in the 16-km range ring, lightning also occurred 823 times in the $9-\mathrm{km}$ range ring $(79 \% \mathrm{CP})$. However, a CG flash was only observed to occur in the inner 9-km range ring 532 times $(51 \% \mathrm{CP})$. Using the $\mathrm{CG}$ only data, 532 of 734 events within the 16-km range ring resulted in a $\mathrm{CG}$ flash in the $9-\mathrm{km}$ range ring $(72 \% \mathrm{CP})$. 
Table 2. Wilcoxon-Mann-Whitney Rank Sum independence testing Z scores and p-values for intercomparision of lead time populations at various ranges $(9,16,32-\mathrm{km})$ and seasons.

\begin{tabular}{|l|r|r|r|}
\hline Range & \multicolumn{1}{|c|}{$32 / 16$} & \multicolumn{1}{c|}{$16 / 9$} & \multicolumn{1}{c|}{$32 / 9$} \\
\hline Wilcoxon-Mann-Whitney (Z) & -1.1947 & -0.0086 & -1.1173 \\
P - value (one tail) & 0.1161 & 0.4966 & 0.1319 \\
\hline Season & spring/summer & summer/autumn & autumn/winter \\
\hline Wilcoxon-Mann-Whitney (Z) & -0.3541 & 2.2522 & -2.4280 \\
P - value (one tail) & 0.3616 & 0.0122 & 0.0076 \\
\hline Season & winter/spring & winter/summer & spring/autumn \\
\hline Wilcoxon-Mann-Whitney (Z) & 1.4855 & 1.4652 & 1.6033 \\
P - value (one tail) & 0.0687 & 0.0714 & 0.0544 \\
\hline
\end{tabular}

Table 3. Number of days per season with lightning, the 25th percentile, median and 75th percentile lead times in minutes for each season. Winter is December through February, spring is March through May, summer is June through August and autumn is September through November.

\begin{tabular}{|l|r|r|r|r|}
\hline \multicolumn{1}{|c|}{ Seasons (16-km Range) } & winter & spring & summer & autumn \\
\hline Number of Days & 70 & 198 & 370 & 96 \\
Lead Time (25th) & 0 & 0 & 1 & 3 \\
Lead Time (median) & 5 & 10 & 7 & 13 \\
Lead Time (75th) & 20 & 24 & 21 & 26 \\
\hline
\end{tabular}

4. Discussion

a. Detection of more lightning because of higher frequency observations

The first important note from the analysis was that $35 \%(532 / 823)$ of the time when lightning was detected by the NALMA within the 9-km range ring (i.e., considered as directly affecting MSFC), zero CG lightning was observed to occur. One great example of this occurred on 27 April 2013 and is highlighted in Fig. 1. These situations primarily develop when large electrified stratiform regions behind mesoscale convective systems (e.g., Carey et al. 2005, Makowski et al. 2013, Lang et al. 2016) or electrified forward anvils of supercell storms (e.g., Fig. 5, Kuhlman et al. 2009, Weiss et al. 2012) are observed over MSFC. Extensive flashes in these types of convection can travel 100s of km (e.g., Lang et al. 2016) and may not produce CG lightning flashes. Other notable examples during this analysis period is during an electrified snow event on 10
January 2011 (Fig. 6). Here a tower initiated lightning flash develops upward from the surface and moves across MSFC without producing any CG activity within the 9-km range ring. It is important to monitor these types of flashes because upward lightning activity from tall objects on the ground sometimes results from preexisting lightning flashes passing over the tall object (e.g., Warner et al. 2012).

\section{b. Comparison to Previous Storm Based Work}

Figure 7 compares the lead time distributions between the $9-\mathrm{km}$ range ring from the present study and the lead time distribution from Buechler et al. (2009). The difference between the two studies is that the present study located at a point and waits for storms to pass by a location (i.e., a Lagrangian approach), whereas the Buechler et al. (2009) study follows the storm along and is independent of any surface locations (i.e., a Eularian approach). The 9-km range ring is chosen because it is the closest spatial domain to that of a thunderstorm. 


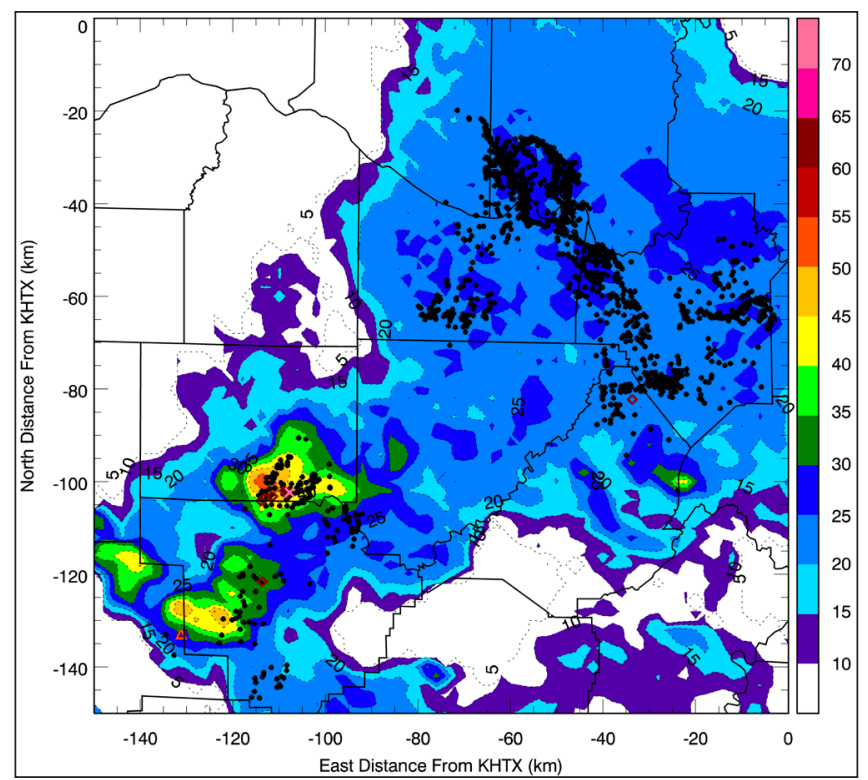

Figure 5. The same NALMA data at 00:01:50 UTC 28 April 2013 (black dots) from Fig. 1 with radar reflectivity (dBZ) from the Weather Service Radar-88D at Hytop, Alabama, at $5 \mathrm{~km}$ contoured and filled.

One similarity between these two studies was the percent of the population where the first flash was observed to be a CG. Twenty-one percent (114/532) of the time there was not precursor lightning in the 9-km domain before a CG occurred. Buechler et al. (2009) showed that a CG flash was observed as the first flash in $18 \%$ of the storms that they studied. Conversely, longer median lead times were observed in the present study than Buechler et al (2009). Longer lead times were not surprising because often thunderstorms moved into the $9-\mathrm{km}$ domain from the $16-\mathrm{km}$ domain. In these scenarios, the NALMA detected lightning in the 9-km domain before the first CG strike occurred within that 9-km domain. Therefore, additional lead time can be realized to protect life and property using the spatial information derived from datasets such as the NALMA. It is likely that radar or electric field measurements are needed to predict the graupel and electric field needed to produce lightning in events where zero lead time was observed on the first CG flash (e.g., Dye et al. 1986, Bringi et al. 1997, Woodard et al. 2012).

\section{c. Translating findings to GLM's resolution}

Although the GLM data on GOES-16 does not have the same spatial resolution of the LMA data used in this study, the methods used in this study are transferrable to the GLM data. Both the LMA and GLM provide spatial

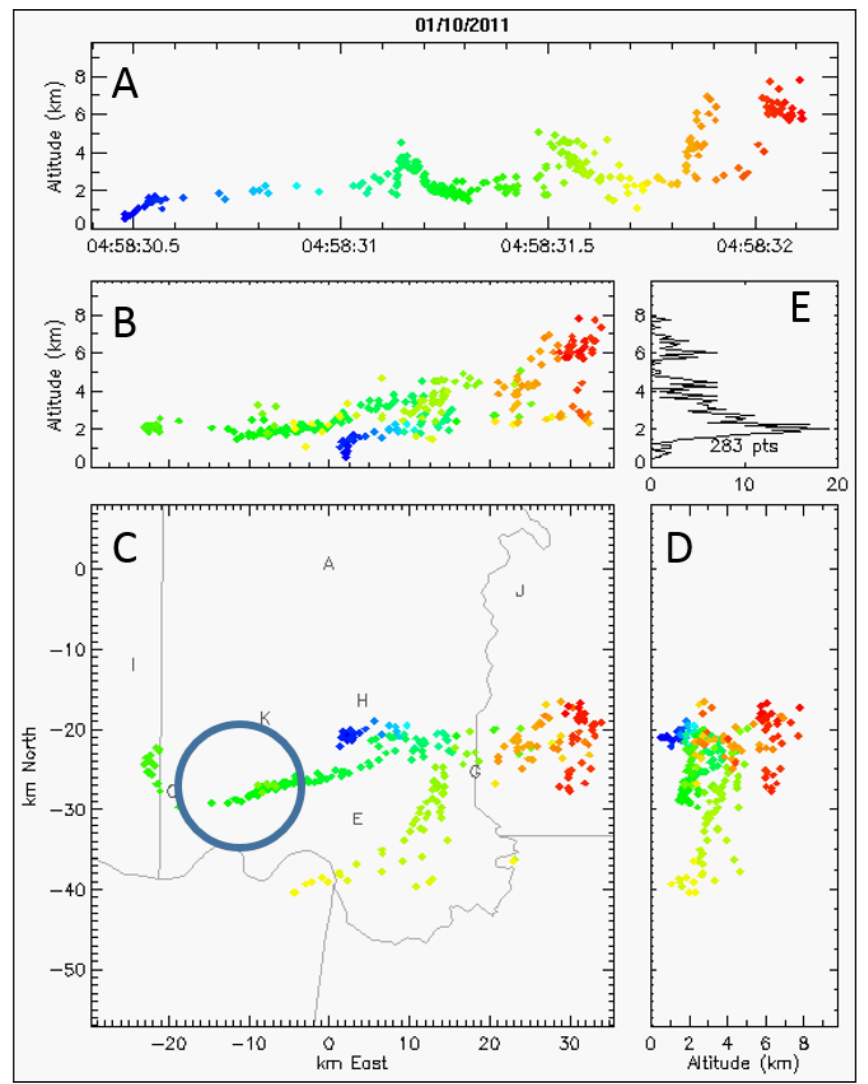

Figure 6. An LMA flash at 04:58:30 UTC 10 January 2011 near Huntsville, Alabama using the NALMA. The blue circle represents the 9-km range ring over MSFC. VHF sources from the LMA are represented by the colored dots and the plot is centered relative to the NALMA center. Panel A shows the VHF source information in time and height, Panel B is the source information in the east direction with height, Panel $\mathrm{C}$ is the VHF source information in plan view in the east and north directions from the LMA Center, Panel D is the VHF sources information in the north direction with height, and Panel E is a histogram of the number of sources with height. Individual LMA stations are noted by capital letters in Panel C. No NLDN detections are observed with this flash.

and temporal information for each lightning flash, which can be used to derive a flash's footprint (e.g., Bruning and MacGorman 2013, Calhoun et al. 2013, Schultz et al. 2015). An example of how a lightning flash observed by NALMA and the NLDN might appear in the GLM framework is found in Fig. 8. Here one can observe that the areal footprint of the flash will be larger than that observed using the higher spatial resolution data from the NALMA. 


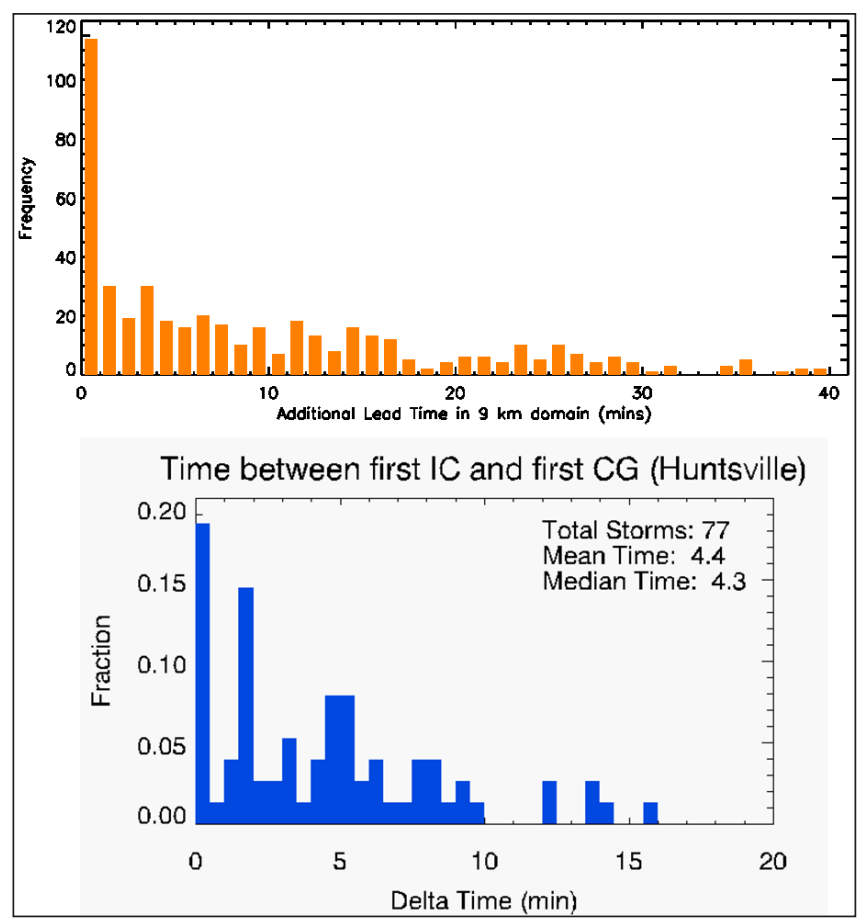

Figure 7. Distribution of lead time between first lightning detected by the NALMA and first CG flash detected by the NLDN (top), and comparison to Buechler et al. (2009) distribution of lead time for 77 storms near Huntsville, Alabama, (bottom).

The reason for the larger footprint is twofold. First, GLM is at a coarser resolution of $8-\mathrm{km} \times 8-\mathrm{km}$ at nadir. Most NALMA VHF source information is within 50 to $500 \mathrm{~m}$ of its correct horizontal location. Second, the NALMA dataset used in this study does not consider the multiple scattering of light through the top of the cloud. GLM measures the light that escapes cloud top from lightning. Because most lightning flashes are buried within cloud structures, multiple scattering will occur as the light from the lightning escapes cloud top. This means that the light emitted by lightning must travel through precipitation and cloud ice. Along this path, the lightning footprint expands in size due to multiple scattering, and the amount of light that reaches the GLM sensor is a function of the altitude of the lightning flash within the cloud (Brunner 2016). Furthermore, it is unclear how parallax may affect the location specific information needed for lightning safety (e.g., Fig. 1 of Bitzer et al. 2016). Seasonal and regional algorithms have been developed to account for parallax issues (Donald Chu, personal communication); however, it is not clear now how parallax might affect the application of GLM for lightning safety.

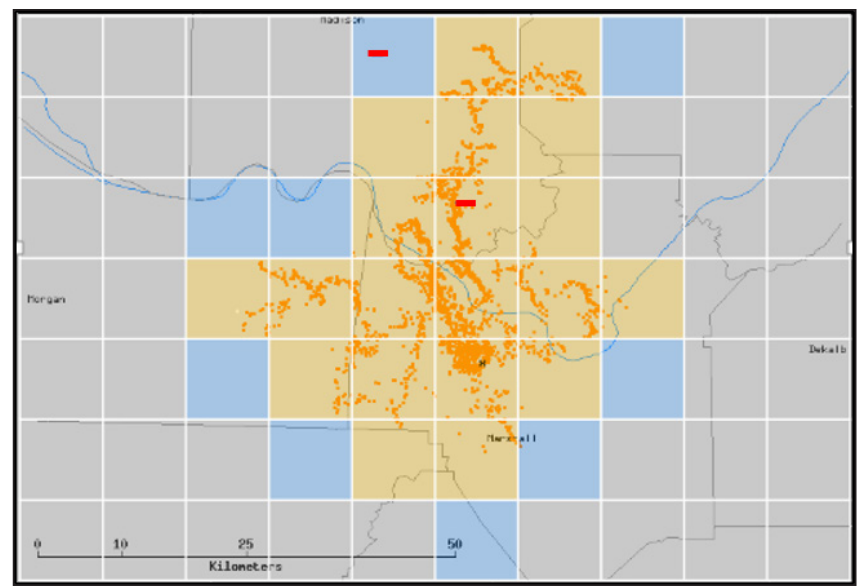

Figure 8. Example schematic from a real lightning flash on 30 March 2002 showing how a lightning flash from NALMA or the NLDN might appear in a GLM framework. Orange dots represent the location of VHF source points from the LMA and red minus signs are negative CG activity detected by the NLDN. Orange boxes represent GLM pixels likely illuminated by this same flash, while blue pixels indicate additional GLM pixels that could be illuminated due to multiple scattering of light through the top of the cloud.

The benefit of GLM is that its performance for lightning detection is nearly uniform across the entire field of view of GOES-16 (Goodman et al. 2013). One major drawback is that GLM cannot discriminate IC flashes from CG flashes on a flash by flash basis (e.g., Koshak and Solakiewicz 2015). Therefore, a combination of GLM and networks such as the NLDN should be combined for decision support services to maximize the advantages of each measurement for lightning safety decision support.

\section{d. Implications for operational decision support services}

The range of lead time and additional down time is consistent across the three range rings examined, so this analysis should be applicable to any warning radius used for decision support. There are slight differences in the $\mathrm{CG}$ predictability at different ranges, as the smaller the range ring used results in a lower CG predictability (Table 4). Differences in lead time relative to warning radius also was documented by Holle et al. (2016) for airport weather warnings.

The effect that this new dataset has on specific applications is yet to fully be realized. In the case of MSFC's EOC, they will now issue lightning alerts if 
Table 4. Number of events observed at the 9,16 and 32-km range rings, the number of events that contained both NALMA and NLDN, NALMA only, and the correct and false prediction of CG activity within each range ring.

\begin{tabular}{|l|r|r|r|}
\hline \multicolumn{1}{|c|}{ Range (km) } & \multicolumn{1}{c|}{$32-\mathrm{km}$} & $16-\mathrm{km}$ & \multicolumn{1}{c|}{$9-\mathrm{km}$} \\
\hline Events Where Lightning was Observed & 1298 & 1043 & 823 \\
NALMA and NLDN & 993 & 734 & 532 \\
NALMA only & 305 & 309 & 291 \\
Correct Prediction of CG activity & $76.50 \%$ & $70.37 \%$ & $64.64 \%$ \\
False Prediction of CG activity & $23.50 \%$ & $29.63 \%$ & $35.36 \%$ \\
\hline
\end{tabular}

any lightning flash is detected by the NALMA inside their $16-\mathrm{km}$ range criteria for seeking shelter from thunderstorm threats. The end user should continue to utilize radar and satellite imagery to fully understand storm motion and evolution relative to lightning warnings. The use of the data should an increase in the amount of advanced warning time personnel have to cease operational activities and seek shelter. There likely will be an increase in the frequency of lightning warnings and the additional time activities will not be permitted to resume because of lightning. These increases are a result of the additional spatial parameter that the total lightning measurements from NALMA and the GLM provide to the forecaster.

Another aspect that is not fully realized is how to determine when the lightning threat has ceased for the location. Current methods by Meyer et al. (2016) use storm based probabilities, which show the probability of a CG flash at a location near a thunderstorm. These probabilities are based on many meteorological variables related to thunderstorm electrification. This method is currently being tested within the probabilistic hazard information (PHI) initiative (Stumpf et al. 2016). The probabilistic information will provide forecasters and decision support personnel a multitude of observations for prediction.

Other methods have not been realized. Figure 9 shows a method from the authors of this paper, framed from the 30/30 rule previously used for lightning safety. The 30/30 rule states that outdoor activities should not occur when thunder can be heard within 30 seconds of the lightning appearing in the sky, or until 30 minutes has passed from the last observed lightning flash. In this figure, boxes that are colored red, yellow and green correspond to the latest time lightning is observed at a specific location. Red shows areas where lightning has

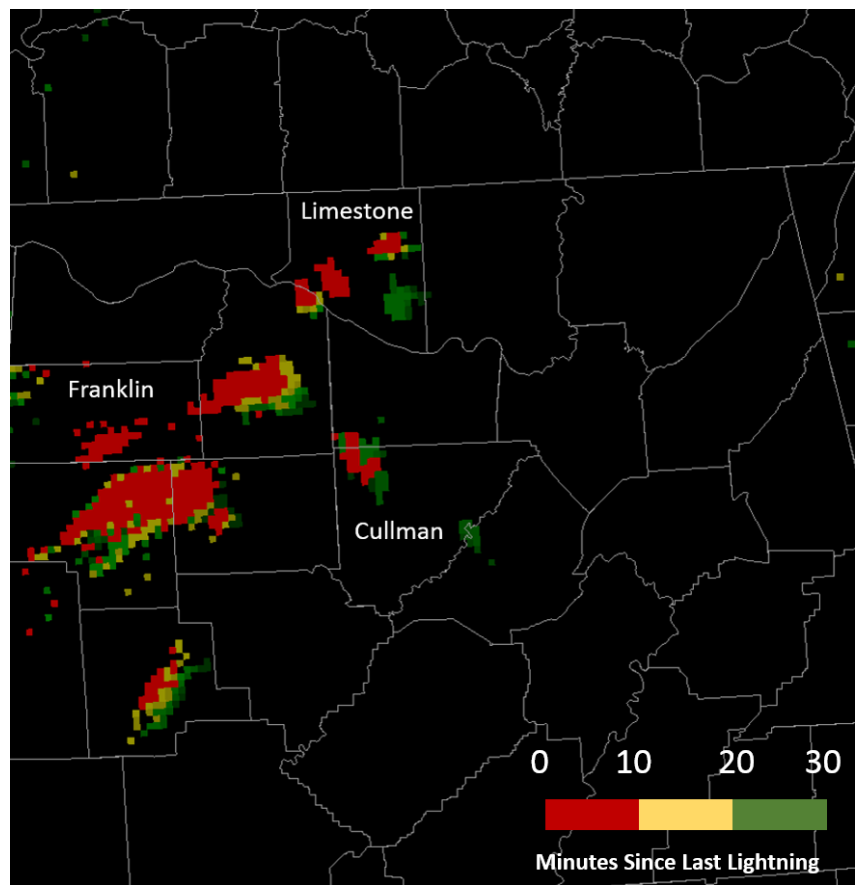

Figure 9. Example $30 / 30$ rule product using total lightning data from the NALMA between 1900 and 1930 UTC 26 August 2016.

occurred in the last $10 \mathrm{~min}$, yellow is where lightning has occurred in the last 10 to $20 \mathrm{~min}$, and green is where lightning has occurred in the last 20 to $30 \mathrm{~min}$. The gridded product only uses the last $30 \mathrm{~min}$ of data, and updates every one or two min (based on the end users' preferences).

Three specific counties have been highlighted in Fig. 9 to demonstrate the concept related to lightning safety. In Franklin Co., AL, the lightning threat is increasing in magnitude as a new thunderstorm has developed in the southern part of this county and lightning from a storm just to the east has entered the far eastern portions of Franklin County. In northwestern Cullman Co., a 
storm that was producing lightning between 20 and 30 min ago (green boxes) has re-intensified in the last 10 min, and has started producing lightning over the same locations once again. Furthermore, a small storm in the extreme southeastern portions of Cullman County is nearing the end of the 30-min waiting period. Similarly, in Limestone Co., AL, storms at various stages of their lifecycle are readily identifiable based on the red, yellow and green colors. Although this approach is very straightforward, it could help decision support services make quick decisions utilizing lightning safety methods that have been in use for many decades.

\section{Conclusions}

Thirteen years of lightning data were synthesized around NASA MSFC in Huntsville, AL to understand the potential implications of the transition of lightning safety protocols from a NLDN CG only solution to a combined NALMA and NLDN CG solution. This work was performed in preparation for total lightning observations from GOES-16's GLM. A total of 2,169 days were identified over the $13-\mathrm{yr}$ period where lightning is observed within $100 \mathrm{~km}$ of MSFC. Of these 2,169 days, $60 \%(1298 / 2169)$ had lightning within the MSFC 32-km range ring, 48\% (1,043/2169) occurred in the $16-\mathrm{km}$ range ring (that triggers a lightning warning to MSFC), and $38 \%(832 / 2169)$ occurred in the $9-\mathrm{km}$ range ring (that is considered to directly impact MSFC operations). The principle findings of this analysis were:

1) The inclusion of NALMA data increased the median lead time on first CG occurrence. The 25 th and 75 th percentile increase in lead time was just more than $0 \mathrm{~min}$ and $23 \mathrm{~min}$ (Fig. 2). Large differences in lead time were not noted if the range ring varied in size.

2) Additional downtime because of lightning activity was incurred using the NALMA dataset. This downtime generally ranged between 0 and 36 min for lightning to clear MSFC (Fig. 3).

3) A CG component was found $65 \%$ of the time that lightning activity was observed to impact MSFC directly. An additional $35 \%$ of the time lightning was observed inside the 9-km range ring, it did not have a CG component. This activity poses a threat to personnel and infrastructure (e.g., Fig. 1).
4) Fifty-one percent of the time lightning was observed by the LMA in MSFC's 16-km range ring (i.e., the range an alert is sent out to seek shelter), a CG occurred in the $9-\mathrm{km}$ range ring. This percentage jumped to $79 \%$ in both the 16 and 9-km range rings if any lightning (IC or CG) was detected by the NALMA. Therefore, $21 \%$ of the time any lightning was detected by the LMA inside the 16-km range ring, no CG lightning was detected in the 9-km range ring, resulting in a false alert.

5) Comparatively, $72 \%$ of the time CG flash was observed in the $16-\mathrm{km}$ range ring, a CG flash also was observed in the $9-\mathrm{km}$ range ring.

6) Twenty-one percent of the time the first lightning flash within the 9-km range ring was a $\mathrm{CG}$, meaning no precursor lightning activity was observed from the NALMA in the 9-km range ring.

7) The largest seasonal differences in lead time were found between the autumn and winter seasons. The smallest difference in lead time was observed between spring and summer seasons.

Once GLM data are available from GOES-16, these findings will be applicable anywhere in the GLM field of view (www.goes-r.gov/education/docs/Factsheet GLM.pdf). The relative unknown is how the use of these lightning data will affect current lightning safety procedures for decision support partners. At minimum, increased lead time on the first CG flash using total lightning data from GLM should benefit decision support partners.

Acknowledgments. The authors would like to thank Mr. Andrew Keys of the MSFC's Office of the Chief Technologist for funding this work. The authors acknowledge partners within the MSFC EOC and facility operations groups, namely Carole Valenti, Brian Koutrous, Megan Hosak, Bob Devlin, and Roy Malone Jr. for valuable insight into the operational needs of MSFC related to lightning protection, and insight into how these results might be implemented in the near future to ensure the safety of personnel and property on MSFC. The authors also thank Ken Cummins, Paul Kriehbel, and Tiffany Meyer for valuable conversations regarding current efforts for lightning safety at various conferences in the autumn of 2016. 


\section{REFERENCES}

Bitzer, P. M., and J. C. Burchfield, 2016: Bayesian techniques to analyze and merge lightning locating system data, Geophys. Res. Lett., 43, 12, 605-12, 613. CrossRef. , and H. J. Christian, 2016: A Bayesian approach to assess the performance of lightning detection systems. J. Atmos. and Oceanic Tech., 33, 563-578. CrossRef.

Bringi, V. N., K. R. Knupp, A. Detwiler, L. Liu, I. J. Caylor, and R. A. Black, 1997: Evolution of a Florida thunderstorm during the Convection and Precipitation/ Electrification Experiment: The case of 9 August 1991, Mon. Wea. Rev., 125, 2131-2160. CrossRef.

Bruning, E. C. and D. R. MacGorman, 2013: Theory and observations of controls on lightning flash size spectra. $J$. Atmos. Sci., 70, 4012-4029. CrossRef.

Brunner, K. N., 2016: Explorations in intracloud lightning and leader processes. M. S. Thesis, University of Alabama-Huntsville, $73 \mathrm{pp}$. [Available online at http:// gradworks.umi.com/10/11/10119606.html]

Buck, T., A. Nag, M. J. Murphy, 2014: Improved cloud-toground and intracloud lightning detection with the LS7002 Advanced Total lightning sensor. TECO-2014WMO Tech. Conf. on Meteorological and Environmental Instruments and Methods of Observation, St. Petersburg, Russia, World Meteorological Organization, P1(9). [Available online at https://www.wmo.int/pages/ prog/www/IMOP/publications/IOM-116 TECO-2014/ Session\%201/P1 9 Buck TotalLightningSensor.pdf.]

Buechler, D. E., R. Boldi, R. J. Blakeslee, and G. T. Stano, 2009: The North Alabama lightning warning product. 2009 Southern Thunder Workshop, Cocoa Beach, FL.

Calhoun, K. M., D. R. MacGorman, C. L. Ziegler, and M. I. Biggerstaff, 2013: Evolution of lightning activity and storm charge relative to dual-Doppler analysis of a highprecipitation supercell storm. Mon. Wea. Rev., 141, 2199-2223. CrossRef.

Carey, L. D., M. J. Murphy, T. L. McCormick, and N. W. Demetriades, 2005: Lightning location relative to storm structure in a leading-line, trailing stratiform mesoscale convective system, J. Geophys. Res., 110, D03105, CrossRef.

Cummins, K. L., and M. J. Murphy, 2009: An overview of lightning location systems: history, techniques, and data uses with an in-depth look at the U.S. NLDN, IEEE Trans. Electromagn. Compat., 51, 499-518. CrossRef.

Dye, J. E., J. J. Jones, W. P. Winn, T. A. Cerni, B. Gardiner, D. Lamb, R. L. Pitter, J. Hallett, and C. P. R. Saunders, 1986: Early electrification and precipitation development in a small, isolated Montana cumulonimbus, J. Geophys. Res., 91, 1231-1247. CrossRef.

Goodman, S. J., and Coauthors, 2013: The GOES-R Geostationary Lightning Mapper (GLM), Atmos. Res., 125-126, 34-49. CrossRef.
Gratz, J. and E. Noble, 2006: Lightning safety and large stadiums. Bull. Amer. Met. Soc., 87, 1187-1194. CrossRef.

Holle, R. L., N. W. Demetriades and A. Nag, 2016: Objective airport warnings over small areas using NLDN cloud and cloud-to-ground lightning data. Weather and Forecasting, 31, 1061-1069. CrossRef.

, R. E. Lopez and C. Zimmerman, 1999: Updated recommendations for lightning safety-1998. Bull. Amer. Met. Soc., 80, 2035-2041. CrossRef.

Koshak, W. J. and R. J. Solakiewicz, 2015: A method for retrieving the ground flash fraction and flash time from satellite lightning mapper observations. J. Atmos. Ocean. Tech., 32, 79--96. CrossRef.

, and Coauthors, 2004: North Alabama Lightning Mapping Array (LMA): VHF source retrieval algorithm and error analyses, J. Atmos. Ocean. Tech., 21, 543-558. CrossRef.

Kuhlman, K. M., D. R. MacGorman, M. I. Biggerstaff, and P. R. Krehbiel, 2009: Lightning initiation in the anvils of two supercell storms, Geophys. Res. Lett., 36, L07802, CrossRef.

Lang, T. J. and Coauthors, 2016: WMO world record lightning extremes: Longest reported flash distance and longest reported flash duration. Bull. Amer. Met. Soc., 119, 1153-1168, CrossRef.

Liu, C., and S. Heckman, 2012: Total lightning data and real-time severe storm prediction. TECO-2012WMO Tech. Conf. on Meteorological and Environmental Instruments and Methods of Observation, Brussels, Belgium, World Meteorological Organization, P5 (10). [Available online at http://www.wmo.int/pages/ prog/www/IMOP/publications/IOM-109_TECO-2012/ Session5/P5 10_Liu_Total_Lightning_Data and_RealTime_Severe_Storm_Prediction.pdf.]

MacGorman, D. R., I. R. Apostolakopoulos, N. R. Lund, N. W. S. Demetriades, M. J. Murphy, and P. R. Krehbiel, 2011: The timing of cloud-to-ground lightning relative to total lightning activity. Mon. Wea. Rev., 139, 38713886. CrossRef.

Makowski, J. A., D. R. MacGorman, M. I. Biggerstaff, W. H. Beasley, 2013: Total lightning characteristics relative to radar and satellite observations of Oklahoma mesoscale convective systems. Mon. Wea. Rev., 141, 1593-1611. CrossRef.

McCaul, E. W., S. J. Goodman, K. M. LaCasse, and D. J. Cecil, 2009: Forecasting lightning threat using cloudresolving model simulations, Weather and Forecasting, 24(3), 709-729. CrossRef

Meyer, T. C., K. M. Calhoun, D. M. Kingfield and D. J. Gagne II, 2016: Using random forest technique to create cloud-to-ground lightning probabilities. 28th Conference on Severe Local Storms, Portland, OR, Amer. Met. Soc., 146. 
Nag, A., M. J. Murphy, W. Schulz, and K. L. Cummins, 2015: Lightning locating systems: Insights on characteristics and validation techniques, Earth and Space Science, 2, 65-93. CrossRef.

Orville, R. E. 2008: The development of the National Lightning Detection Network. Bull. Amer. Met. Soc., 89, 180-190. CrossRef.

Rison, W., R. J. Thomas, P. R. Krehbiel, T. Hamlin, and J. Harlin, 1999: A GPS-based three-dimensional lightning mapping system: Initial observations in central New Mexico. Geophys. Res. Lett., 26, 3573-3576. CrossRef.

Rudlosky, S. D., 2015: Evaluating ENTLN performance relative to TRMM/LIS. J. Operational Meteor., 3(2), 1120. CrossRef.

Schultz, C. J., L. D. Carey, E. V. Schultz, and R. L. Blakeslee, 2015: Insight into the kinematic and microphysical processes that control lightning jumps. Wea. and Forecasting, 30, 1591--1621. CrossRef.

Smith, B. T., R. L. Thompson, J. S. Grams, C. Broyles, and H. E. Brooks, 2012: Convective modes for significant severe thunderstorms in the Contiguous United States. Part I: Storm classification and climatology. Weather and Forecasting, 27, 1114-1135. CrossRef.

Stano, G. T., H. E. Fuelberg, and W. P. Roeder, 2010: Developing empirical lightning cessation forecast guidance for the Cape Canaveral Air Force Station and Kennedy Space Center, J. Geophys. Res., 115, D09205.

CrossRef.

Stumpf, G. J. and Coauthors, 2016: The 2016 Hazard ServicesProbabilistic Hazard Information (HS-PHI) Experiment at the NOAA Hazardous Weather Testbed. 28th Conference on Severe Local Storms, Portland, OR, Amer. Met. Soc., 15B.1. [Available online at https://ams. confex.com/ams/28SLS/webprogram/Paper300179. html]

Thompson, K. B., M. G. Bateman and L. D. Carey, 2014: A comparison of two ground-based lightning detection networks against the satellite-based Lightning Imaging Sensor (LIS). J. Atmos. and Oceanic Tech., 31, 21912205. CrossRef.

Tran, M. D., V. A. Rakov, S. Mallick, 2014: a negative cloudto-ground flash showing a number of new and rarely observed features. Geophys. Res. Lett., 41(18), 65236529. CrossRef.

Warner, T. A., K. L. Cummins, and R. E. Orville, 2012: Upward lightning observations from towers in Rapid City, South Dakota and comparison with National Lightning Detection Network data, 2004-2010, J. Geophys. Res., 117, D19109. CrossRef.

Weiss, S. A., D. R. MacGorman, and K. M. Calhoun, 2012: Lightning in the anvils of supercell thunderstorms, Mon. Wea. Rev., 140, 2064-2079. CrossRef.
Woodard, C. J., L. D. Carey, W. A. Petersen, and W. P. Roeder, 2012: Operational utility of dual-polarization variables in lightning initiation forecasting. Electronic $J$. Operational Meteor., 13(6), 79-102. [Available online at http://nwafiles.nwas.org/ej/pdf/2012-EJ6.pdf.]

Wilks, D. S., 1995: Statistical Methods in the Atmospheric Sciences, 467 pp., Academic Press. 